\title{
Experimentos com modelo de tubo para captação de água fria do mar com movimentos do navio devido a ondas
}

\section{Emanoel H. R. Almeida, ${ }^{\star}$ Jonas N. A Junior*, Marcos V. de Oliveira*, Caio C. O. Trigo, Celso K. Morooka}

\section{Resumo}

Neste trabalho, foram conduzidos experimentos para estudar o comportamento dinâmico de um tubo na vertical (riser) sob movimento do navio devido a ondas. Movimentos harmônicos foram forçados no topo do modelo de riser por meio de dispositivo mecatrônico, representando os movimentos induzidos pelo navio. O tubo encontra-se suspenso no navio com a sua extremidade inferior livre. Testes foram conduzidos com e sem massa concentrada nesta extremidade inferior. Diferentes modos de vibração na direção vertical foram verificados no modelo imerso, e movimentos de oscilação elástica do tubo foram medidos com um sistema ótico para captura de movimentos.

Palavras-chave: Petróleo, risers, plataforma flutuante

\section{Introdução}

A descoberta de grandes acumulações de petróleo nos campos marítimos do pré-sal, e a consequente necessidade de tratamento de maiores volumes de óleo e gás, demandam por melhoria do sistema de resfriamento dos equipamentos de processo em navios e plataformas marítimas de produção. Uma proposta cada vez mais considerada para melhoraria do sistema de arrefecimento da planta de processamento do petróleo e gás é a captação de água fria do fundo do mar com a utilização de tubos verticais denominadas de risers. Sua extremidade superior fica conectada à embarcação de processo na superfície do mar e a extremidade inferior livre e aberta para captação da água fria do mar.

\section{Resultados e Discussão}

Para o estudo do comportamento dinâmico do riser vertical foi projetado e fabricado um modelo em escala reduzida, e medidos forças e movimentos no sistema.
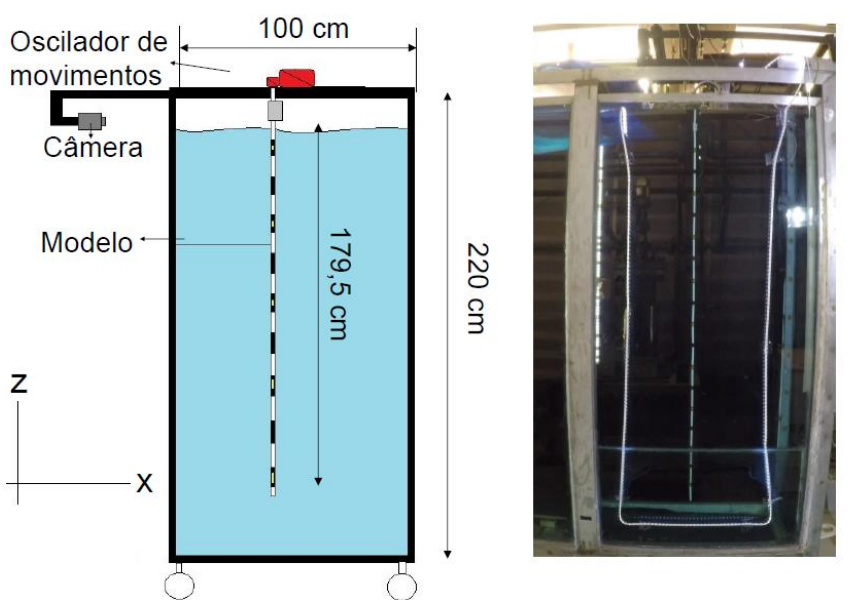

Figura 1 - Tanque com água para experimento com modelo reduzido

Os experimentos foram realizados em um tanque de água, com o modelo de riser confeccionado em silicone. A extremidade superior foi acoplada a um sensor de força e conectado a um dispositivo mecatrônico para geração de oscilações correspondentes aos movimentos do navio em ondas. A extremidade inferior permaneceu livre. Ao longo do comprimento do modelo, foram afixados alvos refletivos para identificação das coordenadas do ponto ao longo do tempo, através da captura de imagem e medição dos movimentos de cada alvo.

Foram inicialmente identificados os principais modos de vibração do modelo através de simulações numéricas em um computador, e posteriormente, movimentos forçados na direção vertical foram gerados no topo do riser. Os testes foram repetidos com e sem massa concentrada na extremidade inferior.

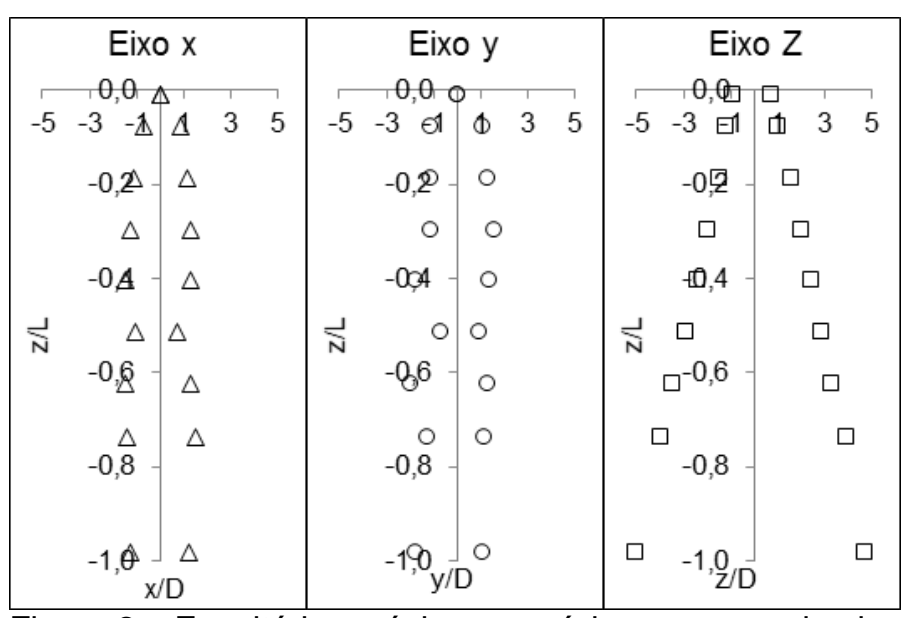

Figura 2 - Envoltórias máximas e mínimas para cada eixo na frequência de oscilação $f=1,899$ e amplitude $10 \mathrm{~mm}$

O modelo apresenta amplitudes de oscilação maiores quando movimentos de topo são forçados próximos das frequências naturais de oscilação vertical do riser. E o modelo apresenta também, elongações maiores no comprimento quando a massa concentrada está presente.

\section{Conclusões}

Foi estudado fundamentos da engenharia de petróleo e sistemas marítimos na produção de óleo e gás, participando do desenvolvimento de atividades práticas no laboratório. Movimentos oscilatórios verticais do riser de captação de água é um fenômeno importante a ser estudado e importante para o seu projeto e construção.

\section{Agradecimentos}

Os autores agradecem a $\mathrm{CNPq}$ e a Pró-reitoria de pesquisa da Unicamp. 